\title{
SENSAÇÃO TÉRMICA E AÇÕES PARA O CONFORTO TÉRMICO: UM ESTUDO DE CASO
}

\section{THERMAL SENSATION AND ACTIONS FOR COMFORT THERMAL: STUDY CASE}

\author{
Louisi Francis Moura ${ }^{1}$; Antônio Augusto de Paula Xavier ${ }^{2}$ \\ ${ }^{1}$ Universidade Tecnológica Federal do Paraná - UTFPR - Ponta Grossa - Brasil \\ louisifrancis@utfpr.edu.br \\ ${ }^{2}$ Universidade Tecnológica Federal do Paraná - UTFPR - Ponta Grossa - Brasil \\ augustox@utfpr.edu.br
}

\begin{abstract}
Resumo
A ergonomia caracteriza-se pela busca da produtividade que não afeta a saúde do trabalhador. Neste cenário, o frio é um agente que interfere no sistema de termorregulação corporal, o qual age de modo a garantir o equilíbrio térmico. Por isso, é relevante que os indivíduos estejam em equilíbrio térmico. Entretanto, mais importante ainda é o conforto térmico dos indivíduos, pois a neutralidade térmica não garante conforto térmico, e este depende da sensibilidade de cada um. Através de um estudo de caso em uma empresa do ramo industrial, este artigo apresenta uma pesquisa com o fim de analisar a sensação térmica dos indivíduos em atividade laboral identificando suas atitudes para garantir seu conforto térmico. Com uso de questionários, os indivíduos apontaram semelhante modo para o seu conforto térmico: uso de roupas. Com essa informação justifica-se a importância do uso de roupas corretas no ambiente de trabalho, considerado um equipamento de proteção individual.
\end{abstract}

Palavras-chave: mecanismo termorregulador corporal, sensação térmica, conforto térmico.

\section{Introdução}

O ser humano tem como uma de suas características a termorregulação corporal. Quando há tendência de aumento de temperatura, por exemplo, o calor deve ser dissipado. Por isso, o organismo trabalha de modo a garantir o equilíbrio térmico, ou seja, para que o ganho seja igual à perda de calor.

A ergonomia térmica considera as limitações fisiológicas e o ambiente. O carregamento de peso, a postura, as condições climáticas e outros, são agentes que interferem no equilíbrio térmico.

Portanto, na busca de melhores condições de trabalho e melhores índices de produtividade, é relevante que as atividades laborais não interfiram negativamente na saúde e segurança do trabalhador. 
Esse artigo tem como objetivo analisar a sensação térmica através de um estudo de caso em uma empresa de pequeno porte e identificar as ações dos indivíduos para garantir seu conforto térmico.

\section{Mecanismo Termorregulador Corporal}

Como uma de suas características quanto à temperatura, o corpo humano gera calor para sua sobrevivência em torno de $37^{\circ} \mathrm{C}$. Por isso, quando numa atividade de maior esforço físico, a temperatura do corpo tende a aumentar, e o sistema termorregulador entra em ação de forma a garantir que a temperatura interna não se altere. Quando em situação de desconforto térmico ligado ao frio, o corpo humano também reage buscando garantir que a temperatura da superfície da pele fique em torno de $34^{\circ} \mathrm{C}$.

Para melhor detalhamento do sistema termorregulador, Prek (2005) explica que o corpo humano garante sua temperatura de acordo com o fluxo de sangue. Esse fluxo bem distribuído caracteriza-se pela vasoconstrição e pela vasodilatação, as quais ordenadas controlam a temperatura e coordenam o aumento ou diminuição da perda de calor com o ambiente.

Devido ao mecanismo termorregulador do organismo, o ser humano constantemente passa por troca térmica entre o corpo e o ambiente. Quando exposto a fontes de calor, essa ação se intensifica.

\section{Variáveis de influência na regulação térmica}

As trocas térmicas com o ambiente são derivadas de quatro variáveis ambientais: temperatura do ar, temperatura radiante média, velocidade do ar e umidade relativa do ar. Além dessas variáveis, duas são também identificadas como variáveis pessoais e subjetivas: taxa metabólica e isolamento térmico da vestimenta.

Identificadas essas variáveis, são delimitados os mecanismos de troca térmica:

- Troca de calor por Condução;

- Troca de calor por Convecção;

- Troca de calor por Radiação;

- Troca de calor por Evaporação.

\subsection{Mecanismos de troca de calor}

Quando o calor é dissipado para o ambiente, ocorre a troca térmica pelo mecanismo de troca por Convecção. Em suma, essa troca caracteriza-se pela presença de um corpo fluido (ar) e um corpo sólido (pele), em contato, com diferencial de temperatura: troca típica. Para o homem dissipar calor é preciso que a temperatura do ar seja inferior a $34^{\circ} \mathrm{C}$, uma vez que essa é a temperatura da 
pele em situação normal.

Outro mecanismo de calor típico do ser humano é a troca por Condução, simbolizado por "K". Ela, em geral, se dá pela troca de calor da pele com a roupa. Sempre do corpo mais quente para o mais frio.

Pode-se concluir então que o corpo humano, através da pele troca calor por Condução, sendo da pele até a roupa, e por Convecção, sendo da roupa até o ar.

Sendo o homem um ser homeotérmico, ou seja, caracteriza-se pela manutenção da temperatura interna do corpo, sua temperatura passa a ser garantida pelo fluxo de calor produzido pelo corpo sendo de mesmo grau do calor cedido ao ambiente. Quando em desequilíbrio, existe a problemática do tempo de exposição que o corpo humano vai assegurar sua temperatura devido à tolerância ao frio e ao calor (AZEVEDO; BARBOSA; SILVA, 2005).

A troca de calor por Radiação, simbolizado por "R", ocorre entre corpos sólidos, mas sem contato e necessariamente com diferencial de temperatura.

A transferência de calor da pele através da convecção e da radiação com o ambiente quente diminui, pois o diferencial de temperatura é baixo. Por isso a perda precisa ocorrer pela difusão da água e sua evaporação. Diferente de um ambiente frio que precisa reter calor e, portanto, o corpo não pode perder calor. A vasoconstrição, neste caso, age de modo a garantir que o fluxo de sangue dirija-se às camadas internas do corpo humano (PREK, 2005).

Portanto, o meio é importante para o equilíbrio térmico. O suor é uma resposta do organismo ao calor excessivo e assim busca refrescar a superfície do corpo. Entretanto, a troca de calor por Evaporação, "E”, é relacionada ao suor ser evaporado, pois somente o suor não é suficiente para refrescar, por isso dada importância do ar não estar saturado.

Almeida e Veiga (2010, p.33) apontam que os estudos em geral quanto a perda de calor do corpo e o meio ambiente estão baseados "no gradiente de temperatura entre a superfície corporal e o meio ambiente, porém com o uso de vestimenta surge um novo fator de estudo, o espaço de ar existente entre a vestimenta e a superfície corporal”.

Os mecanismos de troca de calor são os mesmos, mas com o uso das vestimentas é preciso analisar de modo diferenciado, devido ao isolamento que o EPI (Equipamento de Proteção Individual) proporciona.

\section{Frio}

O homem tem seu sistema termorregulador mais eficaz quanto ao calor do que ao frio. Sendo assim, é importante que o corpo esteja protegido do frio através de roupas isolantes ou permanecendo em ambientes com calefação. Em um ambiente frio e sem proteção necessária o corpo perde calor o que afeta o funcionamento dos órgãos internos quando há diminuição da 
temperatura interna.

A exposição ao frio intenso pode comprometer a saúde e o conforto do trabalhador, além de sua eficiência nas atividades laborais. "A partir da vasoconstrição periférica, para manutenção reguladora da temperatura vital, o frio provoca uma diminuição da atividade muscular e conseqüente redução da habilidade nas mãos” (GALLOIS, 2002, p.11).

É importante salientar que o organismo do ser humano em situação de ambiente quente reage, entre outras características, através da vasodilatação cutânea e em ambiente frio através da vasoconstrição cutânea.

A vasodilatação cutânea refere-se ao fato da pele ficar quente a fim de realizar troca de calor através da irradiação e a condução do calor. A vasoconstrição cutânea caracteriza-se pela pele fria, com o fim de auxiliar a regulação da temperatura interna do corpo, pois o fluxo sanguíneo para a pele fica em torno de $250 \mathrm{ml}$ por minuto e em situação de calor, o fluxo sanguíneo atinge até 1500 $\mathrm{ml}$ por minuto (GALLOIS, 2002).

Como medida preventiva aos possíveis efeitos do frio sobre o homem, a NR 15 (Norma Regulamentadora 15) identifica a utilização de proteção individual e a limitação do tempo em atividade. "Em relação à proteção individual, o trabalhador deve estar provido de casaco adequado, gorro e calçado" (SOUZA; ARAÚJO; BENITO, 1999, p. 437).

Quanto ao uniforme em geral, a norma especifica que deve cobrir o pescoço e a cabeça, além de assegurar ao máximo o isolamento. Quanto maior a velocidade do ar e menor a temperatura do ambiente, maior deverá ser o isolamento proporcionado pelas vestimentas a fim de garantir a proteção do indivíduo.

\section{Procedimentos Metodológicos}

Este artigo apresenta um estudo de caso a fim de identificar características pertinentes quanto à sensação térmica do ser humano atividade de trabalho e os seus mecanismos adaptativos para garantir seu conforto térmico, uma vez que é subjetivo, ou seja, varia de pessoa para pessoa.

O estudo de caso é importante para a pesquisa acadêmica, pois permite a visualização de dados a partir de vivências sendo, portanto, uma estratégia de pesquisa significativa (YIN, 2005).

A pesquisa é classificada como pesquisa básica do ponto de vista de sua natureza e descritiva quanto aos objetivos.

A pesquisa bibliográfica aborda o mecanismo termorregulador do ser humano e as características pertinentes ao frio: como o organismo reage a situações de frio e suas consequências.

$\mathrm{O}$ artigo aborda os mecanismos adaptativos para o frio e os possíveis motivos para alterações de sensação térmica, muitas vezes com mesma taxa metabólica, caracterizando-se também como pesquisa explicativa. 
Para a determinação da Taxa metabólica (expressa em $\mathrm{W} / \mathrm{m}^{2}$ ou met) e do Isolamento térmico da Vestimenta (expressa em clo) foram utilizados os valores indicados pela Norma internacional ISO (International Organization for Standardization). São elas a ISO 7730: Ergonomia de ambiente térmico - Determinação analítica e interpretação do conforto térmico pelo método de cálculo dos índices de PMV e PPD e critérios de conforto térmico; e a ISO 9920: Ergonomia para ambiente térmico - Estimativa de isolamento térmico e resistência de evaporação de água de um conjunto de roupa.

A pesquisa foi realizada em uma indústria de confecção de pequeno porte, com 8 funcionários, sendo esse o número de sua população.

Os funcionários podem ser divididos em operacional e administrativo. Sendo 4 operacionais do sexo feminino, e 4 administrativos, sendo 3 feminino e 1 masculino. Porém, como característica de empresas de pequeno porte, sempre que necessário o pessoal do setor administrativo também desempenha atividades operacionais.

Os funcionários operacionais possuem uniformes, porém seu uso é facultativo. Os uniformes são: blusa de moletom flanelado, calça modelo semi-social, camiseta modelo manga curta de malha poliviscose (poliéster com viscose) e avental tipo bata.

A pesquisa foi realizada em novembro de 2010, no dias 09 e 10, com 2 momentos de pesquisa cada. Vale salientar que a empresa não possui equipamento de ar condicionado.

A pesquisa foi realizada através de questionário constando a indicação de altura, peso, idade, sexo. Incluiu-se o Quadro 1 a seguir, no qual cada pessoa deveria indicar as peças de vestimenta usadas no momento da pesquisa. Pede-se também a descrição da peça utilizada que não constasse no quadro.

A indicação das vestimentas é necessária para a identificação do somatório de Isolamento térmico das vestimentas $\left(\mathrm{I}_{\mathrm{cl}}\right)$.

Quadro 1: Indicação das peças de vestimenta

\begin{tabular}{|c|c|c|}
\hline Cueca & Chinelo/sandália & Jaleco \\
\hline Calcinha e sutiã & Tamanco & Bermuda \\
\hline Meia fina & Calça & Blusa fina \\
\hline Meia cano baixo & Jaqueta & Blusa grossa \\
\hline Meia cano alto & Camiseta & Jaqueta fina \\
\hline Meia calça & Blusa Moletom & Jaqueta média \\
\hline Luvas & Bermuda & Jaqueta grossa \\
\hline Boné & Camiseta & Jaqueta moletom \\
\hline Sapato sola fina & Camisa manga curta & Calça tecido fino \\
\hline Sapato sola grossa & Camisa, manga longa & Calça jeans \\
\hline Tênis sola fina & Camisa Pólo & Calça social \\
\hline Tênis sola grossa & Regata & Calça ginástica \\
\hline
\end{tabular}

Outros:

Fonte: do autor. 
O questionário também apresentava o Quadro 2 a seguir onde cada pessoa deveria indicar como estava sua sensação térmica no momento. A escala corresponde a Escala de Fanger. No Quadro 3, seguindo a mesma escala, a indicação deveria ser feita de acordo com a sensação térmica que cada indivíduo gostaria de estar se sentindo.

Quadro 2: Indicação da sensação térmica

\begin{tabular}{|l|c|c|}
\hline Muito quente & 3 & \\
\hline Quente & 2 & \\
\hline Levemente quente & 1 & \\
\hline Neutro & 0 & \\
\hline Levemente frio & -1 & \\
\hline Frio & -2 & \\
\hline Muito frio & -3 & \\
\hline
\end{tabular}

Fonte: do autor

Quadro 3: Indicação da sensação térmica desejada

\begin{tabular}{|l|c|c|}
\hline Bem mais aquecido & -3 & \\
\hline Mais aquecido & -2 & \\
\hline Um pouco mais aquecido & -1 & \\
\hline Assim mesmo & 0 & \\
\hline Um pouco mais refrescado & 1 & \\
\hline Mais refrescado & 2 & \\
\hline Bem mais refrescado & 3 & \\
\hline
\end{tabular}

Fonte: do autor

Na sequência, era preciso descrever a atividade que o indivíduo estava desempenhando no momento da pesquisa a fim de identificar sua taxa metabólica e, por último, o que pretendia-se fazer para se sentir conforme sensação térmica desejada caso houvesse diferença com a real.

\section{Análise dos resultados}

Inicialmente indica-se que a média de altura da população é de 161,38 cm (centímetros) com desvio padrão de $8,26 \mathrm{~cm}$. O peso médio é $56,66 \mathrm{~kg}$ (quilogramas) e seu desvio padrão de 7,09 kg. A idade média da população é 41,75 anos e desvio padrão de 13,19.

Quanto à idade, destaca-se que a idade média do setor operacional é de 49,5 anos com desvio padrão de apenas 3,41 anos, o que indica com mais precisão a idade comparando com a idade média da população. Diferente da idade do setor administrativo que apresenta média de 34 anos e desvio padrão de 15,3 anos.

\subsection{Atividade desempenhada e sua Taxa metabólica}

Na sequência, apresenta-se a taxa metabólica referente às atividades desempenhadas durante a pesquisa. Os valores de Taxa Metabólica correspondem aos da Norma ISO 7730:2005 (LAMBERTS E XAVIER, 2008). 
Tabela 1: Atividade Desempenhada e respectiva Taxa Metabólica

\begin{tabular}{|c|c|c|c|}
\hline & Atividade desempenhada & Taxa metabó & ISO \\
\hline Indivíduo & Descrição & $\mathrm{W} / \mathrm{m}^{2}$ & met \\
\hline \multirow{4}{*}{1} & Sentado, em refeição & 58 & 1,0 \\
\hline & Em pé, operando máquina eletrônica & 93 & 1,6 \\
\hline & Sentado, em frente ao computador & 70 & 1,2 \\
\hline & Em pé, operando máquina eletrônica & 93 & 1,6 \\
\hline \multirow{4}{*}{2} & Sentada, em frente ao computador e atendendo telefone & 70 & 1,2 \\
\hline & Sentada, atividades de escritório & 70 & 1,2 \\
\hline & Sentada, atividades de escritório & 70 & 1,2 \\
\hline & Sentada, atividades de escritório & 70 & 1,2 \\
\hline \multirow{4}{*}{3} & Sentada, costurando & 70 & 1,2 \\
\hline & Em pé, fazendo serviço de corte de camisetas & 116 & 2,0 \\
\hline & Sentada, costurando & 70 & 1,2 \\
\hline & Sentada, costurando & 70 & 1,2 \\
\hline \multirow{4}{*}{4} & Sentada, costurando & 70 & 1,2 \\
\hline & Sentada, costurando & 70 & 1,2 \\
\hline & Sentada, costurando & 70 & 1,2 \\
\hline & Sentada, costurando & 70 & 1,2 \\
\hline \multirow{4}{*}{5} & Sentada, atividade de escritório & 70 & 1,2 \\
\hline & Sentada, tirando fio em excesso de roupa & 70 & 1,2 \\
\hline & Em pé, inspeção do serviço & 93 & 1,6 \\
\hline & Em pé, inspeção do serviço & 93 & 1,6 \\
\hline \multirow{4}{*}{6} & Sentada, costurando & 70 & 1,2 \\
\hline & Sentada, costurando & 70 & 1,2 \\
\hline & Sentada, próxima a janela, costurando & 70 & 1,2 \\
\hline & Sentada, próxima a janela, costurando & 70 & 1,2 \\
\hline \multirow{4}{*}{7} & Em pé, aviamentando no ferro a vapor & 93 & 1,6 \\
\hline & Em pé, aviamentando no ferro a vapor & 93 & 1,6 \\
\hline & Em pé, aviamentando no ferro a vapor & 93 & 1,6 \\
\hline & Em pé, aviamentando no ferro a vapor & 93 & 1,6 \\
\hline \multirow{4}{*}{8} & Sentada, em refeição & 58 & 1,0 \\
\hline & Em pé, auxiliando serigrafia & 93 & 1,6 \\
\hline & Em pé, auxiliando serigrafia & 93 & 1,6 \\
\hline & Sentada, atividade de escritório & 70 & 1,2 \\
\hline
\end{tabular}

A Tabela 1 mostra as atividades desempenhadas pelos indivíduos no decorrer da pesquisa. Percebe-se que houve pouca alteração da atividade desempenhada entre os indivíduos e que a taxa metabólica encontra-se muito próxima de uma pessoa para outra, segundo os índices de taxa metabólica da Norma ISO 7730 utilizados na tabela.

Em geral, as atividades desempenhadas e a taxa metabólica correspondente encaixa-se em atividade de Classe Metabólica Baixa, como mostra o Quadro 4 a seguir. 
Quadro 4: Níveis de taxa de metabolismo

\begin{tabular}{|c|c|c|}
\hline $\begin{array}{c}\text { CLASSE } \\
\text { METABÓLICA }\end{array}$ & $\begin{array}{c}\text { METABOLISMO } \\
(\text { W/PESSOA })\end{array}$ & EXEMPLOS \\
\hline $\begin{array}{c}0 \\
\text { (repouso) }\end{array}$ & $M<117$ & Repouso \\
\hline $\begin{array}{c}1 \\
\text { (baixa) }\end{array}$ & $117<M<234$ & $\begin{array}{l}\text { Sentado: trabalho manual leve (datilografia, costura); } \\
\text { trabalho de mão e braço (pequenas ferramentas, } \\
\text { inspeções, montagem ou escolha de pequenas peças); } \\
\text { trabalho de braços e pernas (condução normal, } \\
\text { acionamento de pedal). } \\
\text { Em pé: furação (pequenos furos), operação de pequenas } \\
\text { ferramentas elétricas, caminhada a passo lento (abaixo } \\
\text { dos } 3.5 \mathrm{~km} / \mathrm{h} \text { ). }\end{array}$ \\
\hline $\begin{array}{c}2 \\
\text { (moderada) }\end{array}$ & $234<\mathrm{M}<360$ & $\begin{array}{l}\text { Trabalho de mão e braço sustentados (martelar pregos, } \\
\text { enchimentos); trabalho de braço e perna (operação de } \\
\text { carrinhos de mão ou equipamento de construção); } \\
\text { trabalho de tronco e braço (operação de martelo } \\
\text { pneumático, manuseamento intermitente de material } \\
\text { moderadamente pesado); caminhada a passo normal } \\
\text { (entre } 3.5 \text { e } 5.5 \mathrm{~km} / \mathrm{h} \text { ). }\end{array}$ \\
\hline $\begin{array}{c}3 \\
\text { (alta) }\end{array}$ & $360<M<468$ & $\begin{array}{l}\text { Trabalho intenso de tronco e braço; manuseio de } \\
\text { material pesado; serração de madeira pesada; } \\
\text { caminhada a passo apressado }(5,5 \text { a } 7 \mathrm{~km} / \mathrm{h}) \text {; colocação } \\
\text { de blocos de cimento. }\end{array}$ \\
\hline $\begin{array}{c}4 \\
\text { (Muito alta) }\end{array}$ & $M>468$ & $\begin{array}{l}\text { Atividade muito intensa a ritmo acelerado; trabalho } \\
\text { com machado; trabalho de remoção de terras; subida de } \\
\text { rampas, escadas, encostas; caminhada a passo pequeno } \\
\text { e rápido, corrida, caminhada a passo largo (mais de } 7 \\
\mathrm{~km} / \mathrm{h} \text { ). }\end{array}$ \\
\hline
\end{tabular}

Fonte: Águas (2001). Adaptado

$\mathrm{O}$ autor ainda cita a atividade de costura, o que reforça as informações levantadas entre atividade desempenhada e sua taxa metabólica.

Observando cada um dos indivíduos, é possível identificar algumas questões: o Indivíduo 6, por exemplo, durante a pesquisa, desempenhou a mesma atividade, porém em dois momentos destacou-se o fato da sua proximidade com a janela. Isso pode influenciar na sua temperatura uma vez que o vento é um agente de influência na regulação térmica corporal.

Entretanto, a Tabela 2 apresenta a sensação térmica a qual no primeiro momento apresentou Frio (-2) e num segundo momento apresentou sensação de Levemente com Calor (+1).

Diante dessa situação deve-se questionar quanto ao motivo que levou à mudança da sensação uma vez que o lugar e a atividade apresentaram-se as mesmas. Na sequência serão discutidas essas situações.

\subsection{Taxa Metabólica e Sensação Térmica}

Outra situação atípica é a do indivíduo 7 que desempenhou atividade em pé utilizando como instrumento de trabalho o ferro de passar roupa industrial. Esse equipamento tem por característica o calor emitido frequentemente o que pode ter sido a causa do indivíduo apresentar sua sensação 
térmica no grau +2, ou seja, Quente, segundo Escala de Fanger adotada na pesquisa e pela ISO 7730 .

Tabela 2: Relação da Taxa Metabólica e Sensação Térmica

\begin{tabular}{|c|c|c|c|c|}
\hline & \multicolumn{2}{|c|}{ Taxa metabólica ISO } & \multirow{2}{*}{ Sensação } & \multirow{2}{*}{ Sensação desejada } \\
\hline Indivíduo & $\mathrm{W} / \mathrm{m}^{2}$ & met & & \\
\hline \multirow{4}{*}{1} & 58 & 1,0 & -1 & Um pouco mais aquecido \\
\hline & 93 & 1,6 & -1 & Um pouco mais aquecido \\
\hline & 70 & 1,2 & +1 & Assim mesmo \\
\hline & 93 & 1,6 & 0 & Assim mesmo \\
\hline \multirow{4}{*}{2} & 70 & 1,2 & -2 & Mais aquecido \\
\hline & 70 & 1,2 & -1 & Um pouco mais aquecido \\
\hline & 70 & 1,2 & -3 & Bem mais aquecido \\
\hline & 70 & 1,2 & -1 & Um pouco mais aquecido \\
\hline \multirow{4}{*}{3} & 70 & 1,2 & +1 & Assim mesmo \\
\hline & 116 & 2,0 & -1 & Assim mesmo \\
\hline & 70 & 1,2 & -1 & Um pouco mais aquecido \\
\hline & 70 & 1,2 & -2 & Um pouco mais aquecido \\
\hline \multirow{4}{*}{4} & 70 & 1,2 & +1 & Assim mesmo \\
\hline & 70 & 1,2 & +1 & Assim mesmo \\
\hline & 70 & 1,2 & +2 & Assim mesmo \\
\hline & 70 & 1,2 & -1 & Um pouco mais aquecido \\
\hline \multirow{4}{*}{5} & 70 & 1,2 & -1 & Um pouco mais aquecido \\
\hline & 70 & 1,2 & -2 & Bem mais aquecido \\
\hline & 93 & 1,6 & -1 & Um pouco mais aquecido \\
\hline & 93 & 1,6 & +2 & Assim mesmo \\
\hline \multirow{4}{*}{6} & 70 & 1,2 & -1 & Assim mesmo \\
\hline & 70 & 1,2 & -1 & Um pouco mais aquecido \\
\hline & 70 & 1,2 & -2 & Mais aquecido \\
\hline & 70 & 1,2 & +1 & Assim mesmo \\
\hline \multirow{4}{*}{7} & 93 & 1,6 & +2 & Assim mesmo \\
\hline & 93 & 1,6 & +2 & Assim mesmo \\
\hline & 93 & 1,6 & +2 & Assim mesmo \\
\hline & 93 & 1,6 & +2 & Assim mesmo \\
\hline \multirow{4}{*}{8} & 58 & 1,0 & 0 & Assim mesmo \\
\hline & 93 & 1,6 & +1 & Assim mesmo \\
\hline & 93 & 1,6 & +1 & Assim mesmo \\
\hline & 70 & 1,2 & 0 & Assim mesmo \\
\hline
\end{tabular}


A Tabela 2 apresenta a taxa metabólica de cada indivíduo a partir de sua atividade desempenhada e a sensação térmica no mesmo momento. Indica também qual a sensação desejada em cada situação.

É possível observar que os indivíduos em mesma atividade apresentaram sensações térmicas diferenciadas. É caso dos Indivíduos 1, 2, 3, 4, 5 e 6.

O Indivíduo 8, porém, apresentou-se com sensações diferenciadas com taxas metabólicas diferenciadas, porém em todas a resposta foi permanecer com a sensação, ou seja, situação de conforto térmico. Apresentou-se também com sensação térmica Levemente Quente (+1) para atividade de maior taxa metabólica (1,6 met).

\subsection{Relação entre Taxa Metabólica, Sensação Térmica e Somatório de Isolamento Térmico de Vestimenta}

Observando a Tabela 3 a seguir, é possível fazer várias análises entre elas a relação entre a sensação térmica e a vestimenta utilizada, que permite verificar se houve alterações durante o turno de trabalho e se houve diferenças significativas entre as pessoas.

Os valores de Isolamento Térmico de Vestimenta foram obtidos através da Norma ISO 9920:2007, Anexo B, Tabela B.1 correspondente a Valores de Isolamento para roupas em geral.

Tabela 3: Dados de Atividade Desempenhada, Taxa Metabólica, Sensação Térmica, Sensação desejada e Somatório de Isolamento térmico de vestimenta

\begin{tabular}{|c|c|c|c|c|c|c|}
\hline \multirow[b]{2}{*}{ Indivíduo } & \multirow{2}{*}{$\begin{array}{c}\text { Atividade desempenhada } \\
\text { Descrição }\end{array}$} & \multicolumn{2}{|c|}{ Taxa metabólica ISO } & \multirow{2}{*}{$\begin{array}{l}\text { Sensação } \\
\text { térmica }\end{array}$} & \multirow{2}{*}{$\begin{array}{l}\text { Sensação } \\
\text { desejada }\end{array}$} & \multirow{2}{*}{ Somatório $\mathrm{I}_{\mathrm{cl}}$} \\
\hline & & $\mathrm{W} / \mathrm{m}^{2}$ & met & & & \\
\hline \multirow{4}{*}{1} & Sentado, em refeição & 58 & 1,0 & -1 & $\begin{array}{l}\text { Um pouco mais } \\
\text { aquecido }\end{array}$ & 0,89 \\
\hline & $\begin{array}{l}\text { Em pé, operando máquina } \\
\text { eletrônica }\end{array}$ & 93 & 1,6 & -1 & $\begin{array}{l}\text { Um pouco mais } \\
\text { aquecido }\end{array}$ & 0,89 \\
\hline & $\begin{array}{l}\text { Sentado, em frente ao } \\
\text { computador }\end{array}$ & 70 & 1,2 & +1 & Assim mesmo & 1,14 \\
\hline & $\begin{array}{l}\text { Em pé, operando máquina } \\
\text { eletrônica }\end{array}$ & 93 & 1,6 & 0 & Assim mesmo & 1,49 \\
\hline \multirow{4}{*}{2} & $\begin{array}{l}\text { Sentada, em frente ao } \\
\text { computador e atendendo } \\
\text { telefone }\end{array}$ & 70 & 1,2 & -2 & Mais aquecido & 0,8 \\
\hline & $\begin{array}{l}\text { Sentada, atividades de } \\
\text { escritório }\end{array}$ & 70 & 1,2 & -1 & $\begin{array}{l}\text { Um pouco mais } \\
\text { aquecido }\end{array}$ & 1,24 \\
\hline & $\begin{array}{l}\text { Sentada, atividades de } \\
\text { escritório }\end{array}$ & 70 & 1,2 & -3 & $\begin{array}{l}\text { Bem mais } \\
\text { aquecido }\end{array}$ & 0,93 \\
\hline & $\begin{array}{l}\text { Sentada, atividades de } \\
\text { escritório }\end{array}$ & 70 & 1,2 & -1 & $\begin{array}{c}\text { Um pouco mais } \\
\text { aquecido }\end{array}$ & 1,0 \\
\hline \multirow{4}{*}{3} & Sentada, costurando & 70 & 1,2 & +1 & Assim mesmo & 0,8 \\
\hline & $\begin{array}{l}\text { Em pé, fazendo serviço de } \\
\text { corte de camisetas }\end{array}$ & 116 & 2,0 & -1 & Assim mesmo & 0,65 \\
\hline & Sentada, costurando & 70 & 1,2 & -1 & $\begin{array}{l}\text { Um pouco mais } \\
\text { aquecido }\end{array}$ & 0,83 \\
\hline & Sentada, costurando & 70 & 1,2 & -2 & $\begin{array}{l}\text { Um pouco mais } \\
\text { aquecido }\end{array}$ & 0,88 \\
\hline
\end{tabular}




\begin{tabular}{|c|c|c|c|c|c|c|}
\hline \multirow{4}{*}{4} & Sentada, costurando & 70 & 1,2 & +1 & Assim mesmo & 1,27 \\
\hline & Sentada, costurando. & 70 & 1,2 & +1 & Assim mesmo & 1,27 \\
\hline & Sentada, costurando & 70 & 1,2 & +2 & Assim mesmo & 1,22 \\
\hline & Sentada, costurando & 70 & 1,2 & -1 & $\begin{array}{l}\text { Um pouco mais } \\
\text { aquecido }\end{array}$ & 1,22 \\
\hline \multirow{4}{*}{5} & $\begin{array}{l}\text { Sentada, atividade de } \\
\text { escritório }\end{array}$ & 70 & 1,2 & -1 & $\begin{array}{l}\text { Um pouco mais } \\
\text { aquecido }\end{array}$ & 1,09 \\
\hline & $\begin{array}{l}\text { Sentada, tirando fio em } \\
\text { excesso de roupa }\end{array}$ & 70 & 1,2 & -2 & $\begin{array}{l}\text { Bem mais } \\
\text { aquecido }\end{array}$ & 1,44 \\
\hline & Em pé, inspeção do serviço & 93 & 1,6 & -1 & $\begin{array}{l}\text { Um pouco mais } \\
\text { aquecido }\end{array}$ & 1,74 \\
\hline & Em pé, inspeção do serviço & 93 & 1,6 & +2 & Assim mesmo & 1,37 \\
\hline \multirow{4}{*}{6} & Sentada, costurando & 70 & 1,2 & -1 & Assim mesmo & 0,69 \\
\hline & Sentada, costurando & 70 & 1,2 & -1 & $\begin{array}{l}\text { Um pouco mais } \\
\text { aquecido }\end{array}$ & 0,69 \\
\hline & $\begin{array}{l}\text { Sentada, próxima a janela, } \\
\text { costurando }\end{array}$ & 70 & 1,2 & -2 & Mais aquecido & 1,14 \\
\hline & $\begin{array}{l}\text { Sentada, próxima a janela, } \\
\text { costurando }\end{array}$ & 70 & 1,2 & +1 & Assim mesmo & 1,14 \\
\hline \multirow{4}{*}{7} & $\begin{array}{l}\text { Em pé, aviamentando no } \\
\text { ferro a vapor }\end{array}$ & 93 & 1,6 & +2 & Assim mesmo & 1,29 \\
\hline & $\begin{array}{l}\text { Em pé, aviamentando no } \\
\text { ferro a vapor }\end{array}$ & 93 & 1,6 & +2 & Assim mesmo & 1,29 \\
\hline & $\begin{array}{l}\text { Em pé, aviamentando no } \\
\text { ferro a vapor }\end{array}$ & 93 & 1,6 & +2 & Assim mesmo & 1,27 \\
\hline & $\begin{array}{l}\text { Em pé, aviamentando no } \\
\text { ferro a vapor }\end{array}$ & 93 & 1,6 & +2 & Assim mesmo & 1,27 \\
\hline \multirow{4}{*}{8} & Sentada, em refeição & 58 & 1,0 & 0 & Assim mesmo & 1,09 \\
\hline & Em pé, auxiliando serigrafia & 93 & 1,6 & +1 & Assim mesmo & 1,09 \\
\hline & Em pé, auxiliando serigrafia & 93 & 1,6 & +1 & Assim mesmo & 1,09 \\
\hline & $\begin{array}{l}\text { Sentada, atividade de } \\
\text { escritório }\end{array}$ & 70 & 1,2 & 0 & Assim mesmo & 1,09 \\
\hline
\end{tabular}

O indivíduo 5 apresentou mudança de sensação térmica durante o primeiro dia. Apesar da taxa metabólica permanecer inalterada, verifica-se que houve um aumento no somatório do isolamento térmico das vestimentas, o que indica mudança no vestuário, porém a sensação de frio também aumentou, mostrando assim que mesmo com o aumento no número de vestimentas não foi possível garantir o conforto térmico do indivíduo.

No segundo dia de pesquisa, o indivíduo apresentou mudança de sensação de -1 para +2 , na mesma atividade desempenhada, portanto mesma taxa metabólica. O somatório de isolamento térmico de vestimenta diminuiu ao longo do dia, o que indica um aumento de calor devido à atividade desempenhada em pé e movimentação (inspeção do serviço).

O indivíduo 6 apresentou mesmas atividades no segundo dia, com taxa metabólica de 1,6 met, com a observação que estava próximo a janela. Percebe-se no quadro que o somatório de $\mathrm{I}_{\mathrm{cl}}$ apresentou-se maior que no dia anterior, com 1,14 clo e num primeiro momento, a sensação térmica indicada foi de -2 .

Entretanto, no segundo momento da pesquisa, a sensação alterou-se para +1 , sem mudanças de vestimentas ou atividade. Destaca-se que o indivíduo 1 ainda aumentou seu $\mathrm{I}_{\mathrm{cl}}$ vestindo mais peças de roupa e sua atividade também teve taxa metabólica maior. 
Conclui-se que semelhante motivo do indivíduo 6 pode ser a causa dessa mudança: aumento de calor devido à atividade desempenhada, comparando com outros indivíduos (1, 3 e 4) os quais apresentaram diminuição na escala de sensação térmica.

O indivíduo 7 apresentou atividade desempenhada constante e, portanto, sua taxa metabólica não alterou conforme a tabela. Seu somatório de isolamento térmico de vestimenta não teve alteração significativa e sua sensação térmica permaneceu constante.

Ao comparar com os indivíduos 1 e 5, por exemplo, percebe-se mesma taxa metabólica (1,6 met), porém diferente sensação térmica. Isso pode ser pelo fato da atividade desempenhada ser diretamente com um equipamento que emite calor: o ferro de passar roupa industrial. Esse, por ser industrial, tem um peso maior que o doméstico e seu calor também é mais intenso.

O indivíduo 8 manteve seu somatório de isolamento térmico de vestimenta. Sua sensação térmica (entre 0 e +1) alterou-se à medida que a taxa metabólica também alterou-se (entre 1,0 e 1,6 met). Porém, o indivíduo não manifestou desejo de que a sensação indicada se alterasse em nenhum dos casos.

\subsection{Sensação térmica desejada}

Na Tabela 3 constam as sensações térmicas desejadas pelos indivíduos as quais variaram de "Assim mesmo" e "Bem mais aquecido".

No Gráfico 1 a seguir, está a variação de $\mathrm{I}_{\mathrm{cl}}$ do indivíduo 1 na pesquisa. As quatro colunas correspondem aos 4 períodos de pesquisa e os dados do eixo vertical correspondem aos valores do somatório do $\mathrm{I}_{\mathrm{cl}}$.

Analisando juntamente com a Tabela 3 houve alterações significativas no segundo dia, onde o somatório de isolamento foi maior que no primeiro e sua sensação térmica variou de Levemente Quente para Neutro assim como sua taxa metabólica, que variou de 1,2 a 1,6 met respectivamente.

Gráfico 1: Somatório de Isolamento térmico de vestimenta do Indivíduo 1

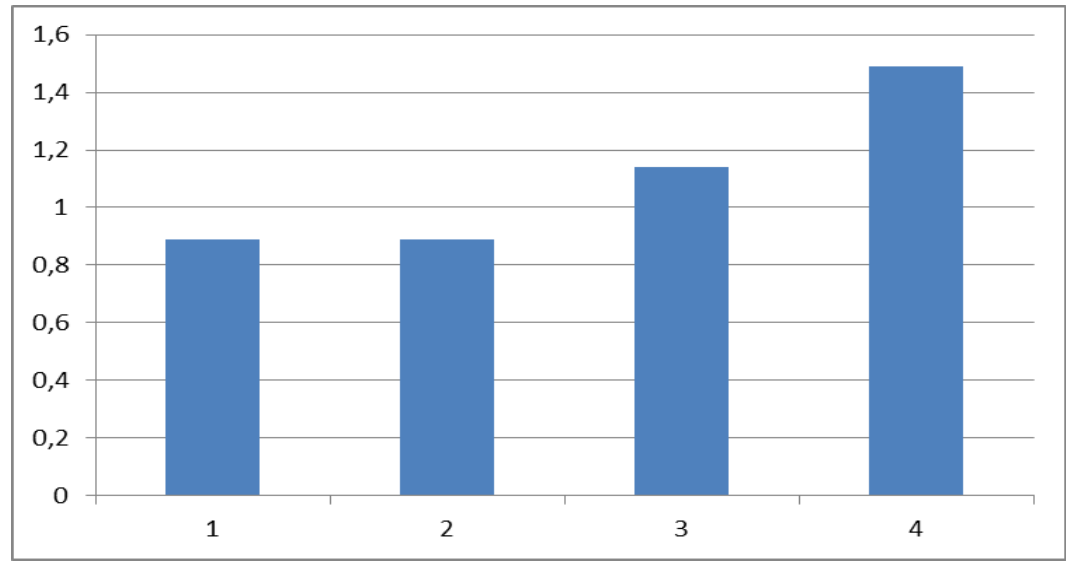

Fonte: o autor 
No primeiro dia (coluna 1 e 2 do gráfico) o indivíduo estava com somatório de $\mathrm{I}_{\mathrm{cl}}$ no valor de 0,89 clo considerado baixo, pois sua sensação foi de Levemente com Frio nos períodos, e taxa metabólica de 1,0 e 1,6 met respectivamente.

Quando questionado quanto às ações para ter a sensação térmica desejada, as respostas foram:

- Voltar ao trabalho (pois encontrava-se em refeição, como aponta a Tabela 3, primeiro período de pesquisa);

- Após o expediente de trabalho tomar um banho quente e vestir um agasalho quente (segundo período de pesquisa);

- Permanecer na mesma atividade (quando sua sensação térmica encontrava-se satisfatória, terceiro período de pesquisa).

$\mathrm{O}$ indivíduo 2 apresentou variações em seu somatório de $\mathrm{I}_{\mathrm{cl}}$ como mostra o Gráfico 2.

Gráfico 2: Somatório de Isolamento térmico de vestimenta do Indivíduo 2

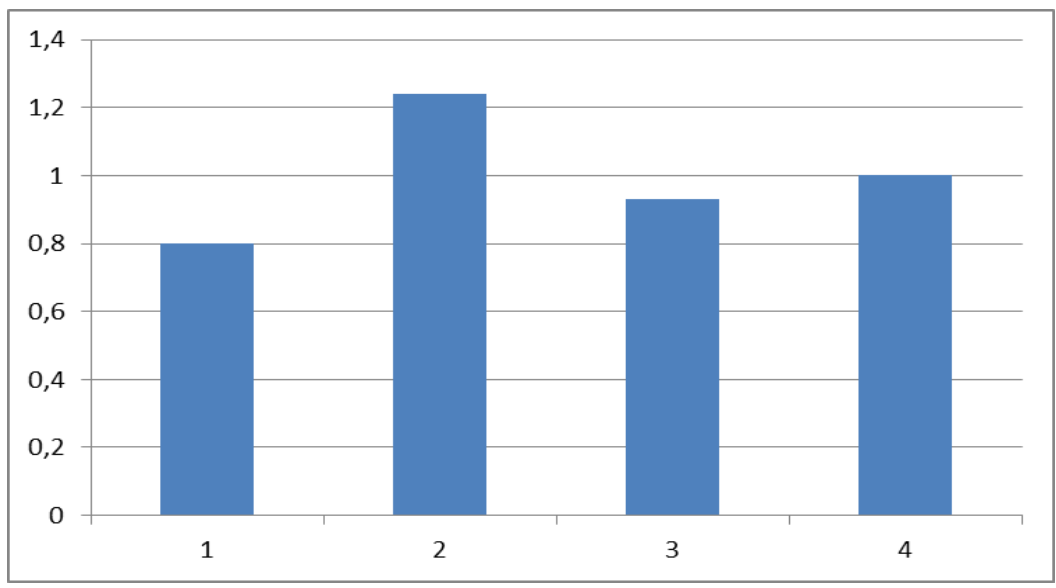

Fonte: o autor

O maior somatório está indicado na coluna 2 com valor de 1,24 clo. De acordo com a Tabela 3 , esse aumento de isolamento térmico através da roupa contribuiu para amenizar o frio sentido, que passou da sensação térmica -2 para -1 .

No terceiro período de pesquisa o indivíduo 2 indicou sensação térmica -3 , ou seja, Muito Frio. Seu somatório de Icl era de 0,93 clo e sua taxa metabólica de 1,2 met. No quarto período, o somatório foi de 1 clo para mesma taxa metabólica: 1,2 met, porém sua sensação térmica já se apresentava Levemente com Frio.

Quando questionado quanto às ações para ter a sensação térmica desejada, as resposta, na ordem da pesquisa:

- Vestir mais blusa, tomar uma bebida quente;

- Movimentar-se;

- Movimentar-se e tomar uma bebida quente; 
- Movimentar-se.

O Gráfico 3 a seguir apresenta o somatório de índices de isolamento térmico de vestimenta do indivíduo 3, que variou entre 0,65 a 0,88 .

Gráfico 3: Somatório de Isolamento térmico de vestimenta do Indivíduo 3

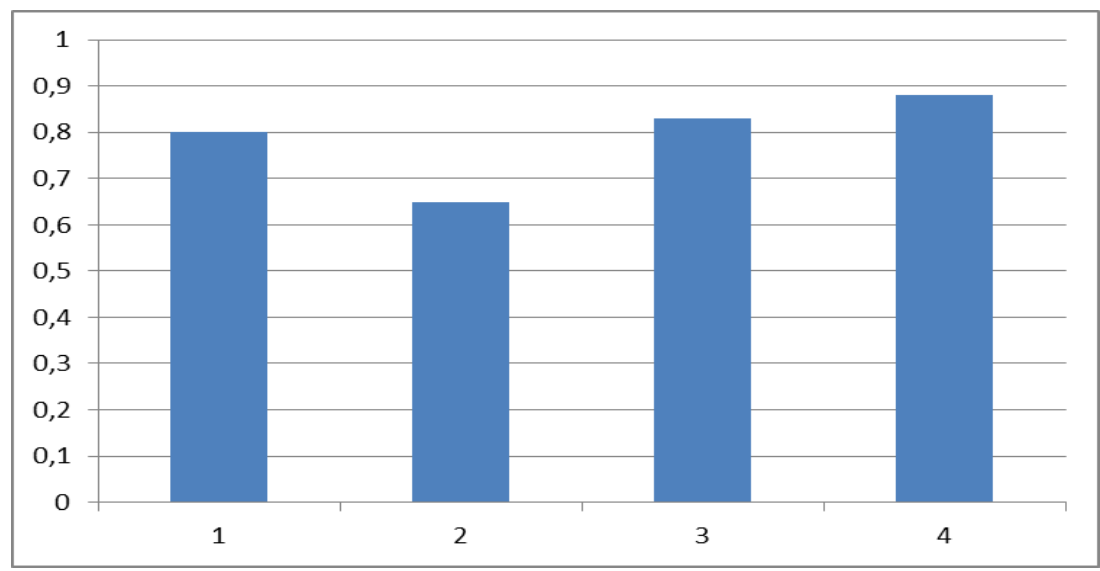

Fonte: o autor

Analisando juntamente com a Tabela 3, o menor valor de $\mathrm{I}_{\mathrm{cl}}, 0,69$, correspondeu à maior taxa metabólica do indivíduo e também da população: 2,0 met. Sua sensação térmica neste momento era de -1 (Levemente com frio), porém essa sensação estava satisfatória.

O maior valor de $\mathrm{I}_{\mathrm{cl}}$ correspondeu ao último período, com 0,88 clo e taxa metabólica de 1,2 met, porém a sensação térmica foi de Frio (-2), não sendo satisfatória, pois o indivíduo indicou que gostaria de estar um pouco mais aquecido.

Apesar dessas diferenças apontadas, o indivíduo, quando questionado quanto à suas ações para atingir a sensação térmica desejada apontou que estava bem assim mesmo. Apenas no último período que sua sensação estava em -2, ou seja, Frio, manifestou-se o desejo de se agasalhar melhor.

O Gráfico 4 a seguir apresenta o somatório de $\mathrm{I}_{\mathrm{cl}}$ para o indivíduo 4. Verifica-se que manteve-se $\mathrm{o} \mathrm{I}_{\mathrm{cl}}$ para cada dia, com variação de 0,05 clo de um dia para o outro.

Gráfico 4: Somatório de Isolamento térmico de vestimenta do Indivíduo 4

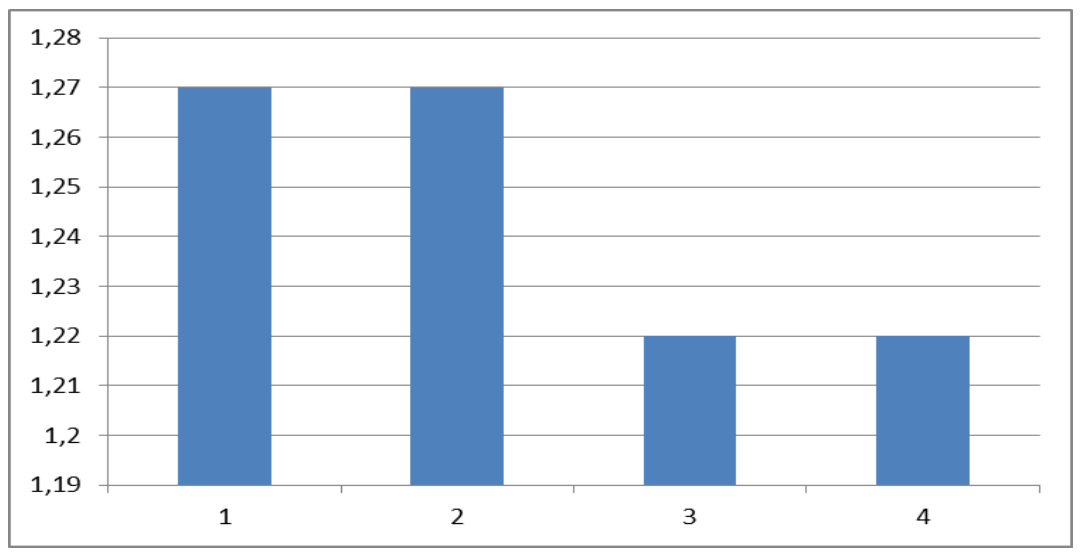

Fonte: o autor 
Nos três primeiros períodos da pesquisa o indivíduo 4 apontou sensação térmica de $+1,+1$ e +2 , respectivamente e satisfação com as mesmas. No quarto período, o qual manteve-se a taxa metabólica assim como os demais e também manteve o Icl do período anterior, a sensação térmica era de -1 , com desejo de estar um pouco mais aquecido.

Nessa última situação, o indivíduo indicou que deveria ter se agasalhado melhor. Como situação atípica, esse indivíduo especificamente é o único que almoça nas dependências da empresa, portanto, suas vestimentas mantiveram-se o dia todo. Diferente dos demais onde se percebe variação no somatório do $\mathrm{I}_{\mathrm{cl}}$.

$\mathrm{O}$ indivíduo 5 apresentou o somatório de $\mathrm{I}_{\mathrm{cl}}$ conforme Gráfico 5 logo a seguir.

Gráfico 5: Somatório de Isolamento térmico de vestimenta do Indivíduo 5

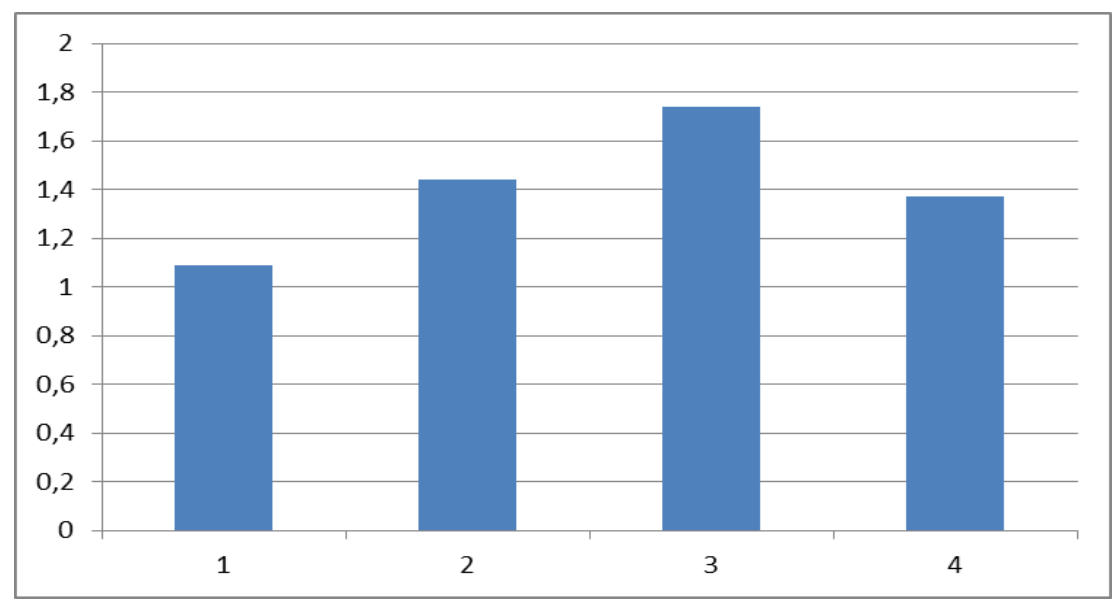

Fonte: o autor

Verifica-se uma variação de 1,09 a 1,74 clo. Os valores de somatório indicados correspondem a sensações térmicas: $-1,-2,-1$ e +2 , respectivamente. As taxas metabólicas foram de 1,2 met para o primeiro dia e 1,6 met para o segundo.

Os maiores somatórios, de 1,74 clo, correspondeu à sensação térmica -1 e de 1,44 que correspondeu à sensação térmica -2 .

Questionado quanto à sensação térmica desejada, o indivíduo indicou a necessidade de agasalhar-se melhor e tomar uma bebida quente.

No Gráfico 6 encontra-se os valores de Icl para o indivíduo 6, os quais mantiveram-se inalterados em cada dia de pesquisa. 
Gráfico 6: Somatório de Isolamento térmico de vestimenta do Indivíduo

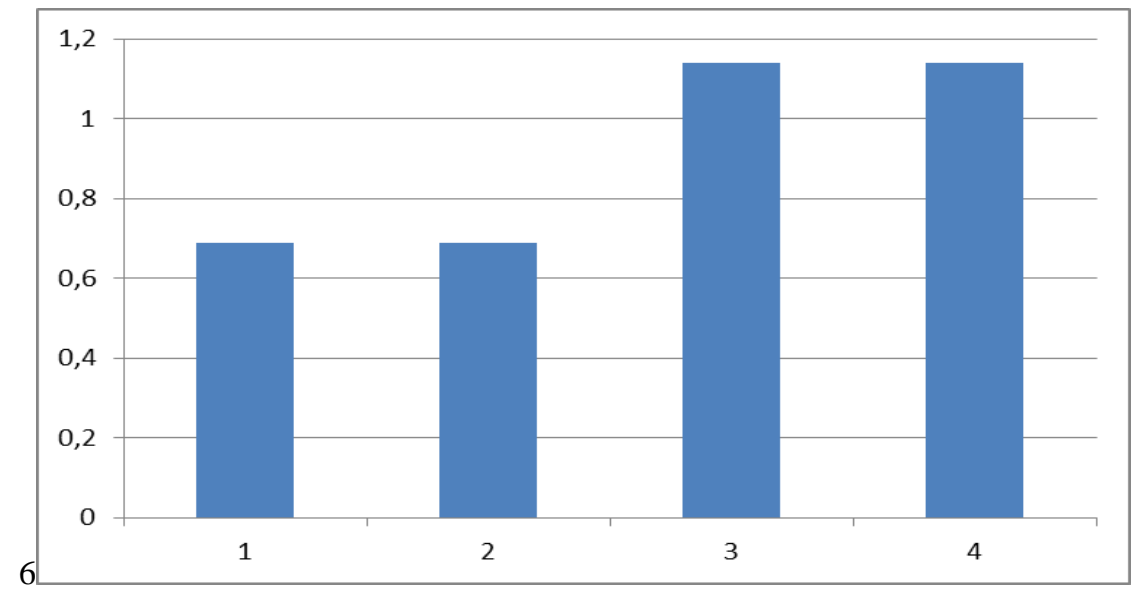

Fonte: do autor

A taxa metabólica do indivíduo 6 foi a mesma para os quatro períodos de pesquisa. Entretanto, destaca-se que no segundo dia a atividade foi desempenhada próxima a janela, como indica a Tabela 3.

Nesse segundo dia, $\mathrm{o} \mathrm{I}_{\mathrm{cl}}$ foi 0,45 clo a mais que no primeiro dia. A sensação térmica foi de -2 e +1 , no segundo dia. Enquanto que no primeiro dia manteve-se em -1 a sensação.

No primeiro e quarto período a sensação estava satisfatória. Nos demais, manifestou-se o desejo de estar mais aquecido.

Apenas no terceiro período, que correspondeu à sensação de -2 , o indivíduo indicou que precisava vestir mais roupa.

O Gráfico 7 a seguir mostra a variação do $\mathrm{I}_{\mathrm{cl}}$ do indivíduo 7, o qual teve alteração de um dia para outro de apenas 0,02 clo.

Gráfico 7: Somatório de Isolamento térmico de vestimenta do Indivíduo

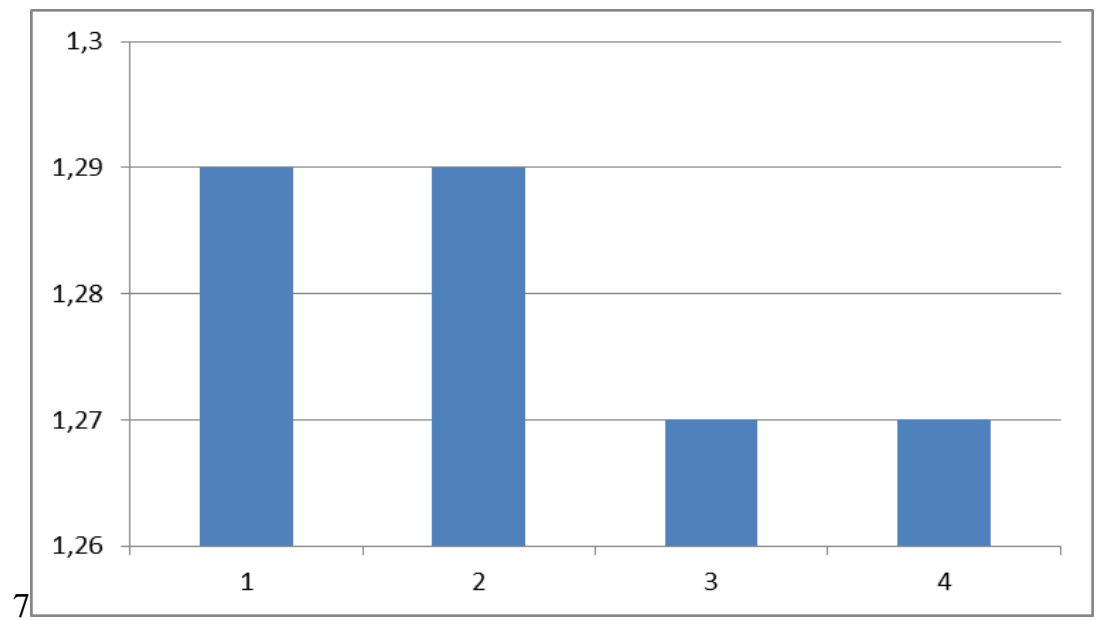

Fonte: do autor 
$\mathrm{O}$ indivíduo 7 diferencia-se dos demais tendo baixa variação de $\mathrm{I}_{\mathrm{cl}}$ e também sensação térmica de +2 nos quatro períodos da pesquisa.

Sua atividade também permaneceu com taxa metabólica de 1,6 met. Essa atividade se diferencia das demais e pode ser a justificativa para a sensação térmica permanecer quente, conforme indicação no item 6.3 deste artigo.

O ferro emite calor por Condução da chapa para o tecido, porém esse calor também é transferido por Radiação, pois com o calor que a roupa ou tecido recebe, ocorre a troca térmica com a pessoa que está operando, conforme conceituação no item 3.1 deste artigo.

O ferro industrial difere do doméstico, entre outras características, por aquecer, além da chapa, o equipamento todo ao longo do período de uso. Em geral, poucos minutos de uso já são suficientes para aquecer o equipamento todo, evidentemente não com a mesma temperatura da chapa, que tem sua potência nominal de 1300 Watts.

Por isso, o cabo para manuseio do ferro também se aquece, transferindo calor por Condução com a pessoa que está operando.

Apesar da sensação térmica que foi indicada ser Quente, o indivíduo não indicou interesse que ela se alterasse se sentindo assim confortável.

$\mathrm{O}$ indivíduo 8 teve seu somatório de $\mathrm{I}_{\mathrm{cl}}$ sem alterações como mostra o Gráfico 8 a seguir.

Gráfico 8: Somatório de Isolamento térmico de vestimenta do Indivíduo

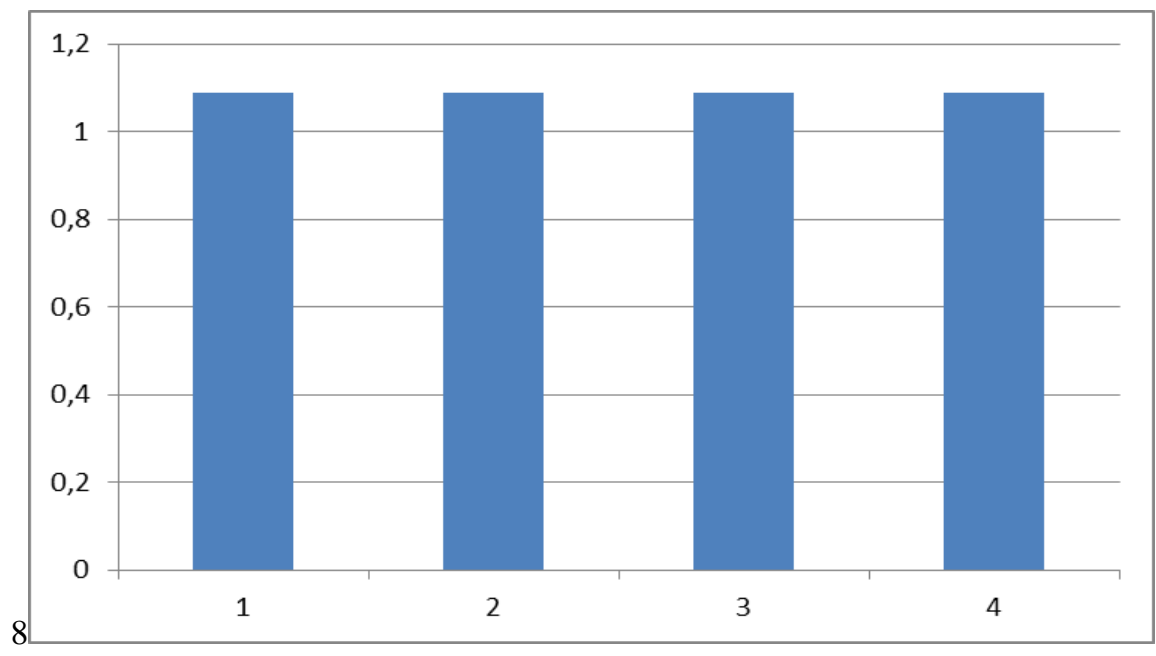

Fonte: do autor

A taxa metabólica variou entre 1,0 a 1,6 met, e a sensação térmica entre 0 e +1 , ou seja, Neutro a Levemente com calor. Contudo, em todos os períodos o indivíduo indicou conforto térmico, sem necessidade de alteração. 


\section{Considerações Finais}

O artigo, através de um estudo de caso, atingiu seu objetivo ao analisar a sensação térmica dos indivíduos envolvidos a fim de identificar as ações para garantir o conforto térmico.

A pesquisa bibliográfica apontou que em situação de frio o organismo, através de seu sistema de termorregulação, é mais propenso a doenças e complicações quando a exposição excede a sua capacidade de garantir o equilíbrio térmico. Conceituou os mecanismos de trocas de calor, os quais influenciam também no equilíbrio térmico.

Os indivíduos envolvidos na pesquisa apresentaram, em geral, situação de frio, mas de baixa intensidade. $\mathrm{O}$ uso de tabelas foi um importante mecanismo para a visualização e comparação dos dados obtidos através de questionário.

Os gráficos também possibilitaram a visualização da variação do somatório de Isolamento térmico de vestimenta das pessoas.

Em geral, os indivíduos apontaram semelhante modo para o seu conforto térmico: uso de roupas. Alguns indicaram a bebida quente.

Com essa informação justifica-se a importância do uso de roupas corretas no ambiente de trabalho. O uniforme é considerado um equipamento de proteção individual, previsto na Legislação Brasileira e, portanto, deve receber atenção pelos empresários e pelos funcionários quanto ao cumprimento do uso.

$\mathrm{O}$ artigo mostrou que, mesmo com taxa metabólica semelhante, os indivíduos apresentam sensação térmica diferente.

O somatório de Isolamento térmico de vestimenta também mostrou que a sensação térmica dos indivíduos é dependente da atividade desempenhada e da sensibilidade.

Isso colabora para provar que neutralidade térmica é uma condição física, mas não significa que a pessoa esteja em conforto térmico, pois é condição da mente, que depende da atividade e expressa satisfação.

\section{Abstract}

The objective of this document is to present to the authors the model of article formatting to be submitted to the Industrial Management Magazine. This document is written in accordance with the model indicated for articles, thus, serves of reference, at the same time where it comments the diverse aspects of the formatting. It observes the instructions and it formats its article in accordance with this standard. We request that it observes with attention the indications contained here, therefore a correct formatting contributes for a good evaluation of its article.

Key-words: magazine; articles; formatting. 


\section{Referências}

ALENCAR, L. H.; ALMEIDA, A. T.; MOTA, C. M. M. Sistemática proposta para seleção de fornecedores em gestão de projetos. Gestão \& Produção, São Carlos, v. 14, n. 3, set./dez. 2007. Disponível em:

<http://www.scielo.br/scielo.php?script=sci_arttext\&pid=S0104-530X2007000300005\&lng=pt\&nrm=iso>. Acesso em: 19 mai. 2008.

ANDUJAR, A. M. Modelo de qualidade de vida dentro dos domínios bio-psico-social para aposentados. 2006.206 f. Tese (Doutorado em Engenharia de Produção) - Programa de Pós-Graduação em Engenharia de Produção, Universidade Federal de Santa Catarina, Florianópolis, 2006.

BUCKHOUT, S; FREY, E.; NEMEC JUNIOR, J. Por um ERP eficaz. HSM Management, v. 3, n. 16, 1999.

CARVALHO, V. R. Qualidade de vida no trabalho. In: OLIVEIRA, O. J. (Org.). Gestão da qualidade: tópicos avançados. São Paulo: Thomson, 2004.

KALAKOTA, R.; ROBINSON, M. E-business: estratégias para alcançar o sucesso no mundo digital. 2. ed. Porto Alegre: Bookman, 2002.

MENEZES, H. Comércio eletrônico para pequenas empresas. Santa Catarina: Visual Books, 2003.

OTANI, M.; MACHADO, W. V. A proposta de desenvolvimento de gestão da manutenção industrial na busca da excelência ou classe mundial. Revista Gestão Industrial, v. 4, n. 2, p. 1-16, abr./jun. 2008.

cross ref

PURCIDONIO, P. M. Práticas de gestão do conhecimento em arranjo produtivo local: o setor moveleiro de Arapongas - PR. 2008. 153 f. Dissertação (Mestrado em Engenharia de Produção) - Programa de Pós-Graduação em Engenharia de Produção, Universidade Tecnológica Federal do Paraná, Ponta Grossa, 2008.

RAMOS, A. S. M.; MIRANDA, A. L. B. Processos de adoção de um sistema integrado de gestão: uma pesquisa qualitativa com gestores da Unimed/Natal. In. ENCONTRO NACIONAL DE ENGENHARIA DE PRODUÇÃO, 23, 2003, Porto Alegre. Anais... Porto Alegre: ABEPRO, 2003.

REZENDE, D. A.; ABREU, F. Tecnologia da informação: aplicada a sistemas de informações empresariais. 2. ed. São Paulo: Atlas, 2001.

SOUZA, C. A.; ZWICKER, R. Implementação de sistemas ERP: um estudo de casos comparados. In. ENCONTRO DA ASSOCIAÇÃO DOS PROGRAMAS DE PÓS-GRADUAÇÃO EM ADMINISTRAÇÃO, 24, 2000, Rio de Janeiro. Anais... Rio de Janeiro: ANPAD, 2000.

\section{Dados dos autores:}

Nome completo: Louisi Francis Moura

Filiação institucional: UTFPR - PG

Departamento: COENP

Função ou cargo ocupado: Professora substituta

Endereço: Avenida Monteiro Lobato, s/n. PG, Pr.

Telefones para contato: (42) 99191910

e-mail: louisifrancis@utfpr.edu.broulouisimail@yahoo.com.br

Nome completo: Antônio Augusto de Paula Xavier

Filiação institucional: UTFPR - PG

Departamento: COENP 
Função ou cargo ocupado: Professor, Doutor.

Endereço: Avenida Monteiro Lobato, s/n. PG, Pr.

Telefones para contato: (42) 32204800

e-mail:augustox@utfpr.edu.br

Enviado em: 01/09/2011

Aprovado em: 02/04/2012 